\title{
Developing a grid-connected DFIG strategy for the integration of wind power with harmonic current mitigation
}

\author{
Hacil Mahieddine, Laid Zarour, Louze Lamri, Nemmour Ahmed Lokmane \\ Electrical Engineering Department, Brothers Mentouri University, Constantine, Algeria
}

\begin{tabular}{|c|c|}
\hline Article Info & ABSTRACT \\
\hline Article history: & \multirow{10}{*}{$\begin{array}{l}\text { The aim of this paper is to present a study of the efficiency of the electrical part of a } \\
\text { wind generation system. Two back-to-back PWM voltage-fed inverters connected be- } \\
\text { tween the stator and the rotor are used to allow bidirectional power flow. The second } \\
\text { inverter grid side, has a role of a power active filter, to eliminate the harmonic gener- } \\
\text { ated by the non linear load, in the same time gives an active and reactive power needed } \\
\text { by the rotor of DFIG. The harmonics of switching frequency in the current stator, pose } \\
\text { a major problem in the moment where commutations in the diode bridge, to solve this } \\
\text { problem, we introduce a small-sized passive LC filter for the purpose of eliminating } \\
\text { high-frequency shaft voltage and grid current from a DFIG driven by a voltage-source } \\
\text { pulse width-modulation rotor inverter controlled with SVM. The control theory is dis- } \\
\text { cussed, and the controller implementation is described. Design criteria are also given. } \\
\text { The results of simulation tests show excellent static and dynamic performances. }\end{array}$} \\
\hline Received Sep 22, 2018 & \\
\hline Revised Apr 17, 2019 & \\
\hline Accepted Apr 25, 2019 & \\
\hline Keywords: & \\
\hline DFIG & \\
\hline Active power filter & \\
\hline Power quality & \\
\hline Wind power & \\
\hline & \\
\hline
\end{tabular}

Corresponding Author:

Hacil Mahieddine,

Departement of Electrical Engineering,

Brothers Mentouri University 1, 25000 Algeria.

Tel: +213661771676

Email: haci12002@yahoo.fr

\section{INTRODUCTION}

Wind power was firstly used by sail ships in the Nile some 5000 years ago. The Europeans used it to grind grains and pump water in the $1700 \mathrm{~s}$ and $1800 \mathrm{~s}$ while in sailing ships [1]. The use of wind turbines to generate electricity can be traced back to the late nineteenth century with the $12 k W$ DC [2]. The stimulus for the development of wind energy in 1973 was the price of oil and concern over limited fossil-fuel resources [1]. There are a few issues to worry about regarding the future energy production in the world. Now, of course, the main driver for use of wind turbines to generate electrical power is the very low $\mathrm{CO}_{2}$ and they are competing with electric utilities in supplying economical clean power in many parts of the world and help limit climate change [3].

Today, Wind energy already plays a significant role in several European nations, and countries like China and India are rapidly expanding their capacity both to manufacture wind turbines and to integrate wind power into their electricity grids. The U.S. led the world in wind power installations for the third year in a row in 2007 [4]. Global wind capacity increased by more than $20,000 M W$, with $5,244 M W$ installed in the U.S. Spain and China were the second and third largest markets last year with $3,515 \mathrm{MW}$ and $3,449 \mathrm{MW}$ of wind power capacity added respectively. According to European Commission targets, wind energy will continue to grow in Europe and will reach $69,900 M W$ in 2010 [5]. In Germany, for example, wind power accounted for almost $10 \%$ of total electricity consumption in 2014 [6]. Such is the growth of wind energy that in the EU, $44 \%$ of new electricity generation capacity installed in 2015 was wind power. Total generation of the world has increased by $17.4 \%$ to amount to $841 T W$ hours in 2015 [7]. According to the Global Wind Energy 
Association, the global wind power installed capacity is $486.66 G W$ by the end of 2016 [8].

Major factors that have accelerated the wind-power technology development are as follows: [2]

(a) High-strength fiber composites for constructing large low-cost blades.

(b) Falling prices of the power electronics.

(c) Variable-speed operation of electrical generators to capture maximum energy.

(d) Improved plant operation, pushing the availability up to 95 percent.

(e) Economy of scale, as the turbines and plants are getting larger in size.

(f) Accumulated field experience (the learning curve effect) improving the capacity factor.

The electromagnetic conversion is usually achieved by induction machines or synchronous and permanent magnet generators. Squirrel cage induction generators are widely used because of their lower cost, reliability, construction and simplicity of maintenance but when it is directly connected to a power network, which imposes the frequency, the speed must be set to a constant value by a mechanical device on the wind turbine [9]. With increased penetration of wind power into electrical grids, DFIG wind turbines are largely deployed due to their variable speed feature and hence influencing system dynamics, it is an induction machine with wound rotor and a four-quadrant ac-to-ac converter setup connected to the rotor winding [10]. Although requiring a gearbox, the DFIG requires a converter of only $25 \%$ of the generator rating for an operating speed range of 0.75 to 1.25 per unit (p.u.) and is considered a lower cost, proven technology solution. DFIGs have long been considered as a good choice for variable speed generation systems [11], [12].

Power electronics loads inject harmonic currents in the ac system and increase overall reactive power demanded by the equivalent load [13], [14],[15], [16]. These distortions, which are caused by harmonics, are one of the major power quality concerns in the electric power industry. And do not meet harmonic current content restrictions, as imposed by several international standards such as IEC 61000 and IEEE519 [17]. Different solutions to minimize the effects of nonlinear loads in electric power systems (nonsinusoidal voltages, harmonic currents) have been proposed in numerous researches. As a mater of fact, there are various types of compensators proposed to increase the power system quality. Traditionally, switched capacitors banks are used to compensate for reactive loads [17], [18], [19], [20]. However, the capacitance of the PFC and the source inductance create a parallel resonance. The other solution is to rectify it with line-commutated switches. Several strategies were proposed for diode rectifiers to further reduce the $(12 m \pm 1)^{t h}$ harmonics [17]. Several other solutions:

(a) Included additional active/passive components within the DC circuit.

(b) Proposed a parallel connected diode rectifier with an active interphase reactor.

(c) Proposed series-connected double three-phase diode rectifiers with auxiliary circuits. A problem of them is that the operation of the auxiliary circuit is very complicated.

(d) Proposed to use a series active filter, and use a square-wave inverters-based dominant harmonic active filter. [17], [19].

Active power filters are gaining more popularity due to their ability of handling higher switching frequencies by using faster power switches [20]. One of the active power filters, the shunt active filter has been researched and developed, and it has gradually been recognized as a feasible solution to the problems created by nonlinear loads. It is used to eliminate the unwanted harmonics and compensate fundamental reactive power consumed by nonlinear loads with injecting the compensation currents into the AC lines [21], [22].

A new technique was launched by P. Poure and all [23] and developed with Abolhassani and all [24], [25] integrated doubly fed electric generator instead of the active filter (IDEA) for variable speed wind energy conversion systems, in another paper Abolhassani and all [26] proposed approach consists of a synchronous generator with modification to its field excitation; Preceded by it Fuyuto Takase and all [27]. It is shown that, by injecting $2^{\text {nd }}, 4^{\text {th }}$ and 6 th harmonic currents into the field, a standard synchronous generator can be modified to generate $5^{\text {th }}$ and $7^{\text {th }}$ harmonics in the stator winding connected to the electric utility. But in a mechanical point of view of this technique, strong torque ripples because of the harmonic currents, the end of the current harmonics compensation in the absence of the wind and heating of the machine by eddy currents and hysteresis within the magnetic circuit with rapid destruction [28], [29].

In response to these concerns, this paper presents the analysis, control and simulation validation of a vector controlled variable speed DFIG supplying a connected grid. Two back-to-back PWM voltage-fed inverters connected between the grid and the rotor are used to allow bidirectional power flow. 
The purpose of the grid side converter is to maintain the dc link voltage constant. It has control over the active and reactive power transfer between the rotor and the grid and used to compensate the harmonics currents, while the rotor side converter is responsible for control of the flux, and thus, the stator active and reactive powers [23], [24], [25], [31].

A vector control approach is adopted which enables the independent control of the active and reactive power flowing between the grid and grid-side converter. An LC-filter between the voltage-source converter VSC and the rotor DFIG is used to reduce the switching frequency harmonics injected in the line currents and eliminate high $d v / d t$, to avoid the overlap phenomenon in Diode Bridge, and ensure a good pace of current. We see also the absence of torque ripple and the continuity harmonic current filtering in wind absence. And generate power to the grid if nonlinear load arrest or both.

\section{DFIG, ELECTRICAL MODEL WITH AN LC FILTER}

The equations of a DFIG in a synchronously rotating $\mathrm{d}-\mathrm{q}$ reference frame, with the $\mathrm{q}$-axis aligned along the stator flux vector position are given by [3]:

$$
\begin{aligned}
& V_{s d}=R_{s} i_{s d}+\frac{d \phi_{s d}}{d t}-\omega_{s} \phi_{s q} \\
& V_{s q}=R_{s} i_{s q}+\frac{d \phi_{s q}}{d t}+\omega_{s} \phi_{s d}
\end{aligned}
$$

Rotor equations:

$$
\begin{aligned}
& V_{r d}=R_{r} i_{r d}+\frac{d \phi_{r d}}{d t}-\omega_{r} \phi_{r q} \\
& V_{r q}=R_{r} i_{r q}+\frac{d \phi_{r q}}{d t}+\omega_{r} \phi_{r d}
\end{aligned}
$$

where $V_{s}=\left[V_{s d} V_{s q}\right]^{T}, V_{r}=\left[V_{r d} V_{r q}\right]^{T}, i_{s}=\left[i_{s d} i_{s q}\right]^{T}$ and $i_{r}=\left[i_{r d} i_{r q}\right]^{T}$, are the stator-side, rotor-side voltage, stator-side current, and rotor-side current, respectively. $\omega$, represent the rotational speed. The superscripts $s$ and $r$ represent the space vectors that referred to stator and rotor references. Contrary, the correlation between the fluxes and the currents, in space vector notation, is given by:

\section{Stator flux}

$$
\begin{gathered}
\phi_{s d}=L_{s} i_{s d}+M i_{r d}=\phi_{s} \\
\phi_{s q}=L_{s} i_{s q}+M i_{r q}=0
\end{gathered}
$$

Rotor flux

$$
\begin{aligned}
& \phi_{r d}=L_{r} i_{r d}+M i_{s d} \\
& \phi_{r q}=L_{r} i_{r q}+M i_{s q}
\end{aligned}
$$

$R, L$, represent the resistance, inductance, respectively. The subscripts $r, s$ stand for rotor side, stator side and $M$ magnetization.

The electromagnetic torque can be expressed using the $d-q$ components as follow:

$$
T_{e}=\frac{p M}{L_{s}}\left(i_{r d} \phi_{s q}-i_{r q} \phi_{s d}\right)
$$

Where $p$ is the number of pole pairs Generally, the dynamic equation for a generator-wind turbine system [31], [32] is used to described the rotor mechanical speed $\omega_{m}$, mechanical torque $T_{m}$, and electromagnetic torque $T_{e}$ as

$$
\frac{d \omega_{m}}{d t}=\frac{p}{J} T_{m}-\frac{p^{2} M}{J L_{s}}\left(i_{r d} \phi_{s q}-i_{r q} \phi_{s d}\right)-\frac{f}{J} \omega_{m}
$$

Where $J$ is inertia constant, $f$ friction coefficient, $T_{e}$ can be calculated from (11), $T_{m}$ is the output torque of wind turbine and can be obtained from the optimum torque-speed curve between the cut-in wind speed and limited wind speed as [32].

$$
T_{m}=\frac{1}{2} \rho A R V_{w}^{2} \frac{C_{p}\left(\beta, \lambda_{i}\right)}{\lambda}
$$


Figure 1 shows $C_{p}$ characteristic of wind turbine. Where $\rho$ is the air density being $1.225 \mathrm{~kg} / \mathrm{m}^{3} ; C p$ is the performance coefficient of the wind turbine which is a function of the tip speed ratio, $\lambda$, and the blade pitch angle, $\beta^{o}$. In this model, the wind speed $V_{w}$ represents the mean value of the upstream wind and $A$ is the area swept by the turbine blades.

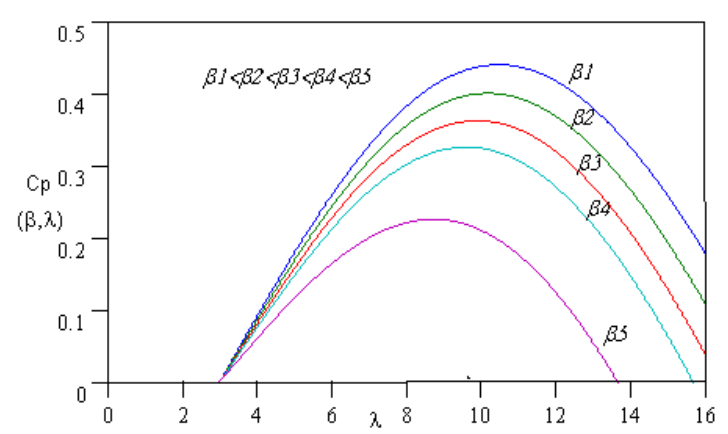

Figure 1. $C_{p}$ characteristic of wind turbine

The function $C_{p}(\lambda, \beta)$ in (12) has been modelled by using the equation proposed in [3].

$$
C_{p}=(0.44-0.0167 \beta) \sin \left[\frac{\pi(\lambda-3)}{15-0.3 \beta}\right]-0.0184(\lambda-3) \beta
$$

The tip-speed- ratio (TSR) is defined as:

$$
\lambda=\frac{D \omega_{r}}{2 v}
$$

$D$ is the diameter of the area covered by the movement of the blades.

The maximum power point is obtained at $C_{\text {pmax }}=0.48$, with optimum tip speed ratio $\lambda_{\beta}=8.1$, and for a minimum blade pitch angle $\beta_{\text {min }}=0$. Figure1 shows the $W_{T}$ power characteristics, for various wind speed values as a function of the rotational speed.

Equations (5) and (6) give [3]:

$$
\begin{gathered}
i_{s d}=\frac{\phi_{s}}{L_{s}}-\frac{M}{L_{s}} i_{r d} \\
i_{s q}=-\frac{M}{L_{s}} i_{r q}
\end{gathered}
$$

The electromagnetic torque $T_{e}$ became:

$$
T_{e}=-\frac{p M}{L_{s}} i_{r q} \phi_{s}
$$

Assuming that the stator resistance is negligible compared with the magnetizing reactance and also that the stator flux vector has a constant magnitude and rotates at a constant angular speed equal to the supply frequency. Equations (1), (2) are simplified to (17) and (18) [33]:

$$
\begin{gathered}
V_{s d}=0 \\
V_{s q}=\omega_{s} \phi_{s}=V_{s}
\end{gathered}
$$

The stator active and reactive powers of a DFIG can thus be derived using equations (14), (15), (17) and (18), giving [23]:

$$
\begin{aligned}
& P_{s}=V_{s d} i_{s d}+V_{s q} i_{s q}=V_{s q} i_{s q}=-V_{s} \frac{M}{L_{s}} i_{r q} \\
& Q_{s}=V_{s q} i_{s d}-V_{s d} i_{s q}=V_{s q} i_{s d}=V_{s}\left(\phi_{s}-\frac{M}{L_{s}} i_{r d}\right)
\end{aligned}
$$


As can be seen, $P_{s}$ and $Q_{s}$ are proportional to and respectively. Provided the magnitude of stator flux is kept constant, both power components can be controlled linearly by adjusting the relative rotor current components.

where the equation (3) and (4) based of equation filter LC show in Figure 2, the current injected in the rotor is $i_{r}$, but $i_{f}$ is the current in output of converter, tension applied in the rotor represented by the capacitor voltage $V_{c}$, and the only harmonic frequency absorbed from the capacitor filter, the general equation of inverter ,LC filter and rotor is given by (20), (21) and (22), where $V_{r d}$ and $V_{r q}$ is the translate frame $a b c$ to $d q$ of $\left[V_{c a} V_{c b} V_{c c}\right]$ [34], [35],[36],[37]. Equivalent circuit of three phase LC filter system in dq frame is depicted in Figure 3.

$$
\dot{x}=\left[\begin{array}{lll}
i_{r} & i_{f} & V_{c}
\end{array}\right]^{T}
$$

and

$$
\begin{gathered}
{[A]=\left[\begin{array}{ccc}
-\frac{R_{r}}{L_{r}} & 0 & -\frac{1}{L_{r}} \\
0 & -\frac{R_{f}}{L_{f}} & -\frac{1}{L_{f}} \\
-\frac{1}{C_{f}} & \frac{1}{C_{f}} & 0
\end{array}\right]} \\
i_{f}=F(p) U+G(p) V
\end{gathered}
$$

With $F$ and $G$ define by the relations (23) and (24) [35], [36], [38]:

$$
\begin{gathered}
F(S)=\frac{1}{a_{1} S^{3}+a_{2} S^{2}+a_{3} S+a_{4}} \\
G(S)=\frac{1+C_{f} S\left(L_{f} S+R_{f}\right)}{\left(L_{r} S+R_{r}\right)\left(1+C_{f} S\left(L_{f} S+R_{f}\right)\right)+\left(L_{f} S+R_{f}\right)}
\end{gathered}
$$

S: Laplace operator

The denominator coefficients in (23) are given by:

$$
a_{1}=L_{r} L_{f} C_{f}, a_{2}=L_{r} R_{f} C_{f}+L_{f} R_{r} C_{f}, a_{3}=L_{r}+L_{f}+R_{r} R_{f} C_{f}, a_{4}=R_{r}+R_{f} \text { If the all }
$$
resistances effects are neglected, relation (23) becomes:

$$
F(S) \approx \frac{1}{L_{r} L_{f} C_{f} S^{3}+\left(R_{r}+R_{f}\right) S}
$$

Finally, the resonance frequency of the LC filter is computed as:

$$
\omega_{a}=\frac{1}{\sqrt{\frac{L_{r} L_{f}}{L_{r}+L_{f}} C_{f}}}
$$

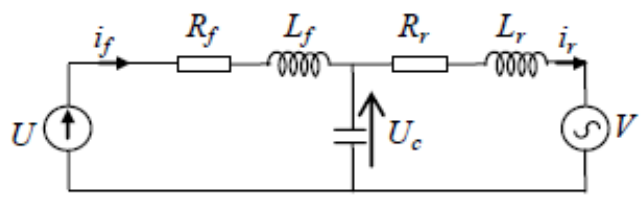

Figure 2. Equivalent circuit of one phase LC filter system

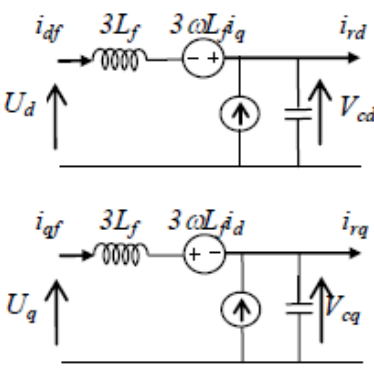

Figure 3. Equivalent circuit of three phase LC filter system in $d q$ frame 


\section{CONTROL OF APF SYSTEM}

Active filters are used to reduce harmonics generated by non-linear industrial loads. Usually the control circuit of the filter detects the non-linear load harmonics and controls the active filter to inject the compensating harmonic in the opposite phase.

Figure 4 shows the general structure of the active filter for non linear load [13], [21],[22].

Let us define $x=i_{h}^{r e f}-i_{g}$ is a state variable, where the complex vector of the reference current $i_{h}^{\text {ref }}$ in the stationary reference frame is given by:

$$
i_{h}^{r e f}=I_{1}^{r e f} \exp j\left(\omega t+\varphi_{1}^{r e f}\right)+\sum I_{m}^{r e f} \exp j\left(m \omega t-\varphi_{m}^{r e f}\right)
$$

with $m=6 k \pm 1, k=1,2,3 \ldots$ and the angular velocity of the fundamental harmonic is $\omega$.

The grid converter allows the DC-bus voltage regulation and the operating at unity power factor. In this case, the currents drawn from the grid are perfectly picture of harmonic currents, sinusoidal or both.

By averaging the switching action of the semiconductor switches and applying the $d q$ transformation to the resulting average model, a large signal average model in $d q$ frame is obtained. The equivalent circuit is shown in Figure 4. The grid converter mathematical model is given by [23], [31]:

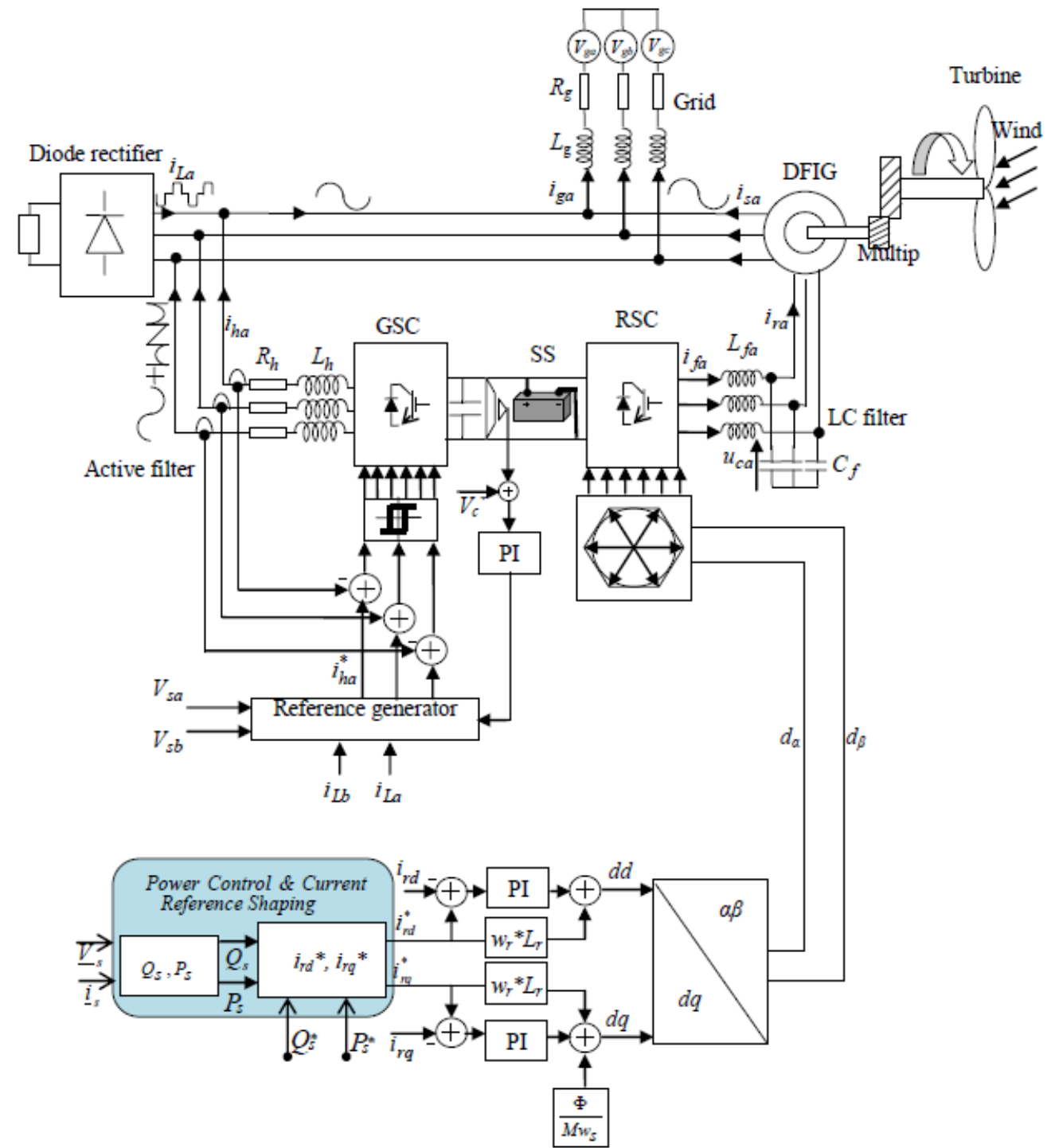

Figure 4. Block diagram of the proposed method 


$$
\begin{gathered}
\frac{d}{d t} i_{d h}=\frac{1}{3 L_{g}}\left(V_{g d}+3 w L_{g} i_{q h}-d_{d h} V_{o}\right) \\
\frac{d}{d t} i_{q h}=\frac{1}{3 L_{g}}\left(V_{g q}-3 w L_{g} i_{d h}-d_{q h} V_{o}\right) \\
\frac{d}{d t} V_{c}=\frac{1}{C_{d}}\left(\frac{3}{2}\left(d_{d h} i_{d h}+d_{q h} i_{q h}\right)-i_{o}\right) \\
V_{o}=V_{c}+R_{c}\left(\frac{3}{2}\left(d_{d h} i_{d h}+d_{q h} i_{q h}\right)-i_{o}\right)
\end{gathered}
$$

With $L=L_{g}+L_{h}$ and $R=R_{g}+R_{h}$

So, the current $i_{o}$ is given by:

$$
\begin{gathered}
i_{o}=\left(\frac{3}{2}\left(d_{d f} i_{d f}+d_{q f} i_{q f}\right)\right) \\
i_{h}=i_{h}+i_{p}
\end{gathered}
$$

Where

$i_{h}$ harmonic current

$i_{p}$ power current

$$
\begin{gathered}
i_{o}^{\prime}=d_{d h} i_{d h}+d_{q h} i_{q h} \\
i_{o}=S_{1} i_{a f}+S_{2} i_{b f}+S_{3} i_{c f} \quad \text { and } \quad i_{o}^{\prime}=S_{1}^{\prime} i_{a h}+S_{2}^{\prime} i_{b h}+S_{1}^{\prime} i_{c h}
\end{gathered}
$$

$S$ rotor converter switch (RSC), $S^{\prime}$ grid converter switch (GSC)

\section{RESULTS AND ANALYSIS}

The proposed control strategy is applied to a WECS equipped with a $12 k W$ DFIG. The system parameters is presented in the appendix, Table 1 and Table 3 . The switching frequency of the RSC is chosen equal to $2.5 \mathrm{kHz}$ and GSC controlled with $6 \mathrm{~A}$ hysteresis band.

In the first time the non linear load is not connected, the grid side inverter gives an active and reactive power needed by the rotor of DFIG, Figure 5, Figure 6 show the performance of implantation of the LC filter between the rotor and RSC with parameters are given in Table 2 of the Appendix, where the ripple caused by the commutation frequency is eliminate in the stator current, active and reactive power and torque. Figure 7 and Figure 8, the grid current spectrum, before and after put of LC filter, prove the enhancement of the grid current THD which is reduced from about $5.83 \%$ to $2.6 \%$.

At time $t=0.5 \mathrm{~s}$ and $t=0.6 \mathrm{~s}$ an step in the reference of active power and reactive from $5 \mathrm{Kw}$ to $10 K w$ and $2 k V$ ar to $5 K V$ ar respectively, present the good response to this control and stability of system.

In the second study at $t=1 s$ the diode bridge connected sizing in the Table 4 of the appendix, the grid side inverter give power and compensate harmonic current Figure 9 and figure 10 illustrate the performance of the proposed method where the THD reduced from $27.88 \%$ to $3.89 \%$ in the norm recommended.

Figure 11 showed the correct tracking of the harmonic current to the reference, and the advent of the LC filter where cancellation of the switching frequency at the stator current. The DC capacitor voltage is maintained constant practically at its command value of $900 \mathrm{~V}$ before $t=0.3 \mathrm{~s}$, by the control of the GSC as shown in Figure 11. During active filtering operation, one can notice small oscillations of $V_{d}$ at a frequency of $300 \mathrm{~Hz}$. However, these oscillations do not affect the DC bus stability. 


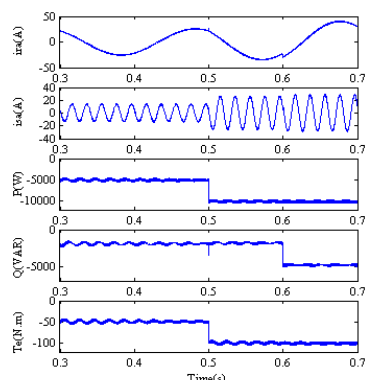

Figure 5. $i_{r a}$ phase a rotor current, $i_{s a}$ phase $a$ stator current, $P$ and $Q$ active and reactive power, $T_{e}$ electromagnetic torque without LC filter
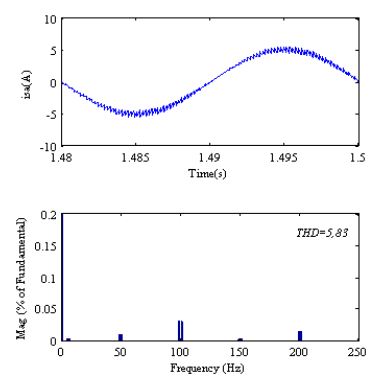

Figure 7. $i_{s a}$ phase $a$ stator current and spectrum analysis without LC filter
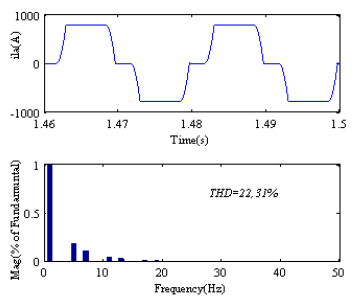

Figure 9. $a$ nonlinear load current and spectrum analysis

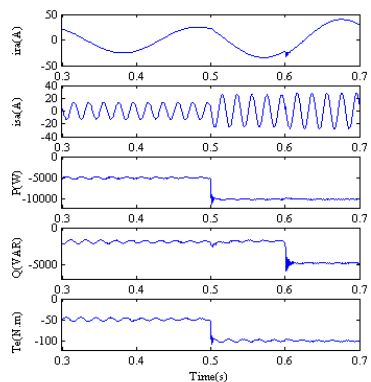

Figure 6. $i_{r a}$ phase $a$ rotor current, $i_{s a}$ phase $a$ stator current, $P$ and $Q$ active and reactive power, $T_{e}$ electromagnetic torque with LC filter
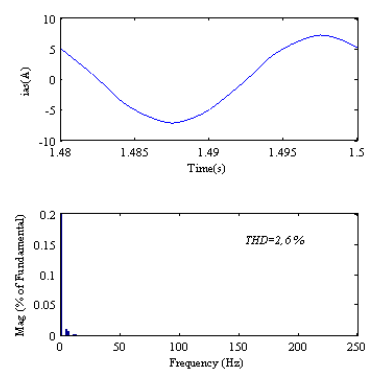

Figure 8. $a$ stator current and spectrum analysis with LC filter
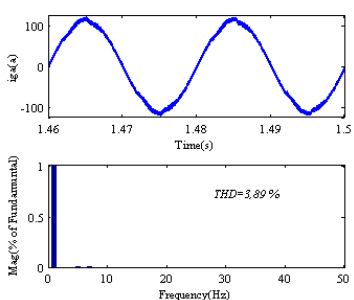

Figure 10. $i_{g a}$ phase $a$ grid current and spectrum analysis

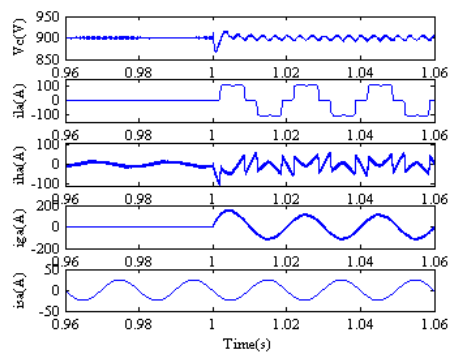

Figure 11. $V_{c}$ DC voltage, $i_{L a}$ Load current, $i_{h}$ grid side inverter current, $i_{g a}$ grid current, and $i_{s a}$ effects of the LC filter on the DFIG's stator current waveform 


\section{CONCLUSION}

In this paper, a novel approach has been proposed to manage and improve the quality of the grid power using a WECS equipped by a DFIG. The RSC is controlled in such a way to manage between production of maximum active power and power quality improvement without any over-rating. The performance of the grid side converter achieves an active and reactive green power source with active filtering capability. The proposed topology has been shown to be capable of reducing the torque ripple and providing an almost sinusoidal voltage to the grid with an optimum SVM method is proposed to obtain the best line-current THD with reduced switching losses with an LC filter normally required at the output of a PWM inverter rotor to assist in the switching device commutation and switching harmonic filtering. Simulation results show excellent steady state and dynamic performances of the developed prototype.

\section{REFERENCES}

[1] LM Wind Power. Wind power's development over time. https://www.lmwindpower.com

[2] Bin Wu, Yongqiang Lang,Navid Zargari, "Power Conversion and Control of Wind Energy Systems" John Wiley and Sons.2011, 2011.

[3] Manale Bouderbala, Badre Bossoufi, Ahmed Lagrioui, Mohammed Taoussi, "Direct and indirect vector control of a doubly fed induction generator based in a wind energy conversion system," International Journal of Electrical and Computer Engineering (IJECE),Vol. 9, No. 3, June 2018, pp. 1531- 1540.

[4] Angelika Pullen, Steve Sawyer, "Global Wind 2007 Report," Global Wind Energy Council.

[5] Takashi Ikegami, Chiyori T. Urabe, "Numerical definitions of wind power output fluctuations for power system operation," Renewable Energy, Volume 115, January 2018, Pages 6-15.

[6] Alexander Zerrahn, "Wind Power and Externalities," Ecological Economics, Volume 141, November 2017, Pages 245-260.

[7] https://www.evwind.es/2016/06/23/8-countries-that-produce-the-most-wind-energy-in-the-world/56665

[8] Christopher Jung, Dirk Schindler, Jessica Laible, "National and global wind resource assessment under six wind turbine installation scenarios," Energy Conversion and Management, 156 (2018), pp 403-415.

[9] Adel Abdelbaset, Yehia S. Mohamed. Urabe, "Wind Driven Doubly Fed Induction Generator," Power Systems book series, pp 7-20, Springer International Publishing AG 2018.

[10] Peng, Bo and Zhang, Feng and Liang, Jun and Ding, Lei and Liang, Zhenglin and Wu, Qiuwei, "Coordinated control strategy for the short-term frequency response of a DFIG-ES system based on wind speed zone classification and fuzzy logic control," International Journal of Electrical Power \& Energy Systems, Volume 115, 2019, pp 363-378.

[11] Chetan S. Rawal, Anwar M. Mulla, "An AC-AC Converter for Doubly Fed Induction Generator Driven By Wind Turbine," International Journal of Scientific and Research Publications, Volume 4, Issue 12, December 2014.

[12] Karakasis, Nektarios E and Mademlis, Christos A, "High efficiency control strategy in a wind energy conversion system with doubly fed induction generator," Renewable Energy, Vol. 125, 2018, pp 974-984.

[13] Shamala N, C. Lakshminarayana, "Performance Enhancement in Active Power Filter (APF) by FPGA Implementation," International Journal of Electrical and Computer Engineering (IJECE), Vol. 8, No. 2, April 2018, pp. 689-698.

[14] Wang, Lei and Lam, Chi-Seng and Wong, Man-Chung, "Unbalanced control strategy for a thyristorcontrolled LC-coupling hybrid active power filter in three-phase three-wire systems," IEEE Transactions on Power Electronics, vol. 32, no. 2, 2017, pp 1056-1069.

[15] Bosch, Swen and Staiger, Jochen and Steinhart, Heinrich, "Power quality improvement using VLLMS based adaptive shunt active filter," CPSS Transactions on Power Electronics and Applications, vol. 65, no. 62, 2018, pp 4943-4952.

[16] Ray, Pravat Kumar, "Predictive current control for an active power filter with lcl-filter," IEEE Transactions on Industrial Electronics, vol. 3, no. 2, 2018, pp 154-162.

[17] Shoji Fukuda, Shigete Ueda, "Auxiliary Supply Assisted Harmonic Suppression for 12-Pulse PhaseControlled Rectifiers," The 2010 International Power Electronics Conference - ECCE ASIA - Sapporo, Japan 21-24 June 2010.

[18] Nikunj Shah, "Harmonics in power systems - Causes, effects and control," Siemens Industry , 2013,usa.siemens.com/lv-drives. 
[19] Shoji Fukuda, Issei Hiei, "Auxiliary Supply-Assisted 12-Pulse Phase-Controlled Rectifiers With Reduced Input Current Harmonics," IEEE Transactions on Industry Applications, vol. 44, no. 1, january/february 2008.

[20] M. Tavakoli Bina, E. Pashajavid, ”An efficient procedure to design passive LCL-filters for active power filters," Electric Power Systems Research, 79 (2009) 606-614.

[21] Rajasekharareddy Chilipi, Naji Al Sayari, "Third order sinusoidal integrator (TOSSI)-based control algorithm for shunt active power filter under distorted and unbalanced voltage conditions," Electrical Power and Energy Systems , 96 (2018) 152-162.

[22] Yacine Terriche, Josep M. Guerrero, "Performance improvement of shunt active power filter based on non-linear least-square approach," Electric Power Systems Research, 160 (2018) 44-55.

[23] P. Poure, S. Saadate, "Filtrage dynamique d'harmoniques d'un réseau électrique a l'aide d'une machine a double alimentation commandée par le rotor,” J. Phys. III France , 5 (1995) 2087-2099.

[24] T. Abolhassani, Peyman Niazi, "Sensorless Integrated Doubly-Fed Electric Alternator/Active Filter (IDEA) for Variable Speed Wind Energy System," Proc. IEEE Industry Application Society 2003, 2003.

[25] T. Abolhassani, Prasad Enjeti, "Integrated Doubly-Fed Electric Alternator/Active Filter (IDEA), a Viable Power Quality Solution, for Wind Energy Conversion Systems," Conference Record of the 2004 IEEE Industry Applications, 2004. 39th IAS Annual Meeting, Seattle, WA, USA,3-7 Oct. 2004.

[26] T. Abolhassani, A. Toliyat, "An electromechanical Active Harmonic Filter," IEMDC 2001, Boston, MA, 2001.

[27] Fuyuto Takase, Masatoshi Toininaga, "Harmonic Compensation Using a Synchronous Machine with Resonant Field Circuits," IEEE Transactions on Energy Conversion, Vol. 12, No. 2, June 1997.

[28] Andreas Krings, Juliette Soulard, "Overview and comparison of iron loss models for electrical machines," International Conference on Ecological Vehicles and Renewable Energies, Monaco, March 25e28, 2010.

[29] Eyhab El-Kharashi, "Detailed comparative study regarding different formulae of predicting the iron losses in a machine excited by non-sinusoidal supply," Energy, 73 (2014) 513-522.

[30] Damian Kowal, Peter Sergeant, "Rotor speed control of doubly fed induction generator wind turbines using adaptive maximum power point tracking," IEEE Transactions on Magnetics, vol. 51, no. 1, January 2015.

[31] A. Gaillard a, P. Poure, "Variable speed DFIG wind energy system for power generation and harmonic current mitigation," Renewable Energy , 234 (2009) 1545-1553.

[32] Jiabing Hu, Heng Nian, "Direct Active and Reactive Power Regulation of DFIG Using Sliding-Mode Control Approach," IEEE Transactions on Energy Conversion, Vol. 25, no. 4, December 2010.

[33] Dinh-Chung Phan, Shigeru Yamamoto, "Rotor speed control of doubly fed induction generator wind turbines using adaptive maximum power point tracking," Energy, 111 (2016) 377-388.

[34] K. Sahnouni, F. B. Ammar, "An improved variable structure control of a shunt active filter," Seventh International Conference on Power Electronics and Variable Speed Drives (IEE Conf. Publ. No. 456), 1998, Pages: $46-50$.

[35] Mohamad Alaa Eddin Alali, 'Contribution à l'Etude des Compensateurs Actifs des Réseaux Electriques Basse Tension," , Docteur de l'Université Louis Pasteur - Strasbourg I, Discipline : Génie électrique, 12 Septembre 2002.

[36] Fantino, Roberto A and Busada, Claudio A and Solsona, Jorge A, "Observer-Based Grid-Voltage Sensorless Synchronization and Control of a VSI-LCL Tied to an Unbalanced Grid," IEEE Transactions on Industrial Electronics, Vol. 66, no. 7, 2019, pp 4972-4981.

[37] Gomes, Camilo C and Cupertino, Allan F and Pereira, Heverton A, "Damping techniques for gridconnected voltage source converters based on LCL filter: An overview," Renewable and Sustainable Energy Reviews, Vol. 81, 2018, pp 116-135.

[38] Jingyang Fang, Guochun Xiao, "An LCCL Filter and Its Application to a Half-Bridge APF," 9th International Conference on Power Electronics-ECCE Asia, June 1 - 5, 2015 / 63 Convention Center, Seoul, Korea. 


\section{Appendix}

Simulation is performed using the following :

Parameters:

Table 1. DFIG parameters

\begin{tabular}{lcr}
\hline Variable & designation & value \\
\hline $\mathrm{L}_{s}$ & Stator inductance & $0.084 \mathrm{H}$ \\
$\mathrm{L}_{r}$ & Rotor inductance & $0.081 \mathrm{H}$ \\
$\mathrm{M}$ & Mutual inductance & $0.078 \mathrm{H}$ \\
$\mathrm{R}_{s}$ & Stator winding resistor & 0.455 \\
$\mathrm{R}_{r}$ & Rotor winding resistor & $0.62 \Omega$ \\
$\mathrm{J}$ & Combined moment of inertia of machine and turbine & $0.3125 \mathrm{~kg} \cdot \mathrm{m}^{2}$ \\
$\mathrm{P}$ & Number of pole pairs & 2 \\
\hline
\end{tabular}

Table 2. GSC and LC filter parameters

\begin{tabular}{lcr}
\hline Variable & designation & value \\
\hline $\mathrm{R}_{h}$ & GSC Resistance & $0.0062 \Omega$ \\
$\mathrm{L}_{h}$ & GSC Inductance & $100 \mu F$ \\
$\mathrm{R}_{f}$ & LC Resistance & $1.7 \mathrm{~m} \Omega$ \\
$\mathrm{L}_{f}$ & LC Inductance & $0.0203 \mathrm{H}$ \\
$\mathrm{C}_{f}$ & LC capacitor & $8.1057 \mu \mathrm{F}$ \\
$\mathrm{C}_{d}$ & DC bus capacitor & $300 \mu \mathrm{F}$ \\
\hline
\end{tabular}

Table 3. Grid parameters

\begin{tabular}{lcr}
\hline Variable & designation & value \\
\hline $\mathrm{L}_{g}$ & Grid inductance & $0.000115 \mathrm{H}$ \\
$\mathrm{R}_{g}$ & Grid resistor & $0.0005 \Omega$ \\
$\mathrm{F}$ & frequency & $50 \mathrm{~Hz}$ \\
$\mathrm{~V}_{g}$ & Grid voltage & $400 \mathrm{~V}$ \\
\hline
\end{tabular}

Table 4. Nonlinear Load parameters

\begin{tabular}{lcr}
\hline Variable & designation & value \\
\hline $\mathrm{L}_{d}$ & DC side Inductance & $0.005 \mathrm{H}$ \\
$\mathrm{R}_{d}$ & DC side Resistance & $5 \Omega$ \\
\hline
\end{tabular}

\section{BIOGRAPHIES OF AUTHORS}

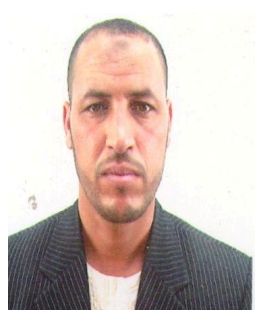

Mahieddine Hacil He received his Engineering degree in Electrical Engineering from the Department Electrical Engineering of Larbi Ben M'hidi University, Oum El Bouaghi, Algeria, in 1999. and M.S, Ph.D. degrees from the Department of Electrical Engineering of Mentouri Brothers University, Constantine, Algeria, in 2004, 2012 respectively, where he now works as a professor. His research area is on Power electronic, Power quality and Renewable energy sources.

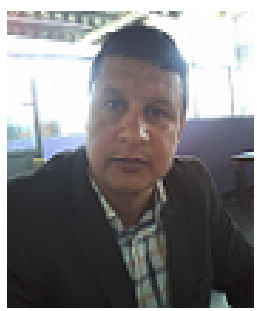

Laid Zarour He received his B.S., M.S., and Ph.D. degrees from the Department of Electrical Engineering of Mentouri Brothers University, Constantine, Algeria, in 2002, 2005, and 2010, respectively, where he now works as a professor. His research interests are power electronics and applications in photovoltaic systems.

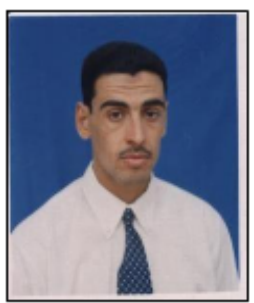

Lamri Louze He received his B.S., M.S., and Ph.D. degrees from the Department of Electrical Engineering of Mentouri Brothers University, Constantine, Algeria, in 2000, 2003, and 2010, respectively, where he now works as a professor. His research area is on Diagnostic, Power electronic and Renewable energy sources. 